\title{
THE EFFECT OF COMMUNICATION BARRIER ON THE PRODUCTIVITY AND PERFOMANCE OF EMPLOYEES
}

\author{
Dr. C K GOMATHY, Mr. B SANDEEP SAI, Mr. A PRADEEP REDDY, Mr. Ch NITHISH \\ Sri Chandrasekharendra Saraswathi Viswa Mahavidyalaya, Kanchipuram
}

\begin{abstract}
Correspondence is the method involved with communicating data and normal comprehension starting with one individual then onto the next. Correspondence in the working environment is basic to laying out and keeping up with quality working connections in associations. This paper talks about the correspondence interaction, hindrances to correspondence, and gives rule to heads to further develop correspondence adequacy.
\end{abstract} Keywords: Communication, Effectiveness, Administrators, Workplace performance, productivity

\section{INTRODUCTION}

Central and imperative to every single regulatory capacity, correspondence is a method for communicating data and getting one's point across by another or others (Sanchez and Guo, 2005). Conveying actually is a workmanship and should be drilled really at work environment for better result and effective accomplishment of objectives of an association. Correspondence is difficult for managers since they are answerable for giving data, which brings about proficient and viable execution in associations. The investigation of correspondence is significant, on the grounds that each authoritative capacity and movement includes some type of immediate or aberrant correspondence. Regardless of whether arranging and coordinating or driving and observing, overseers speak with and through others. This suggests that each individual's relational abilities influence both individual and hierarchical viability (Brun, 2010; Summers, 2010). It appears to be sensible to infer that one of the most restraining powers to hierarchical adequacy is an absence of successful correspondence (Lutgen-Sandvik, 2010). Great relational abilities are vital to ones accomplishment as a chairman (Yate, 2009). It is thusly fundamental for heads to attempt to become powerful communicators. This paper examines the correspondence interaction and the significance of correspondence in the working environment and gives rules on how heads can further develop their relational abilities and adequacy. 


\section{COMMUNICATION PROCESS}

Correspondence Communication can be characterized as the method involved with sending data and normal comprehension starting with one individual then onto the next (Keyton, 2011). It is the creation or trade of considerations, thoughts, feelings, and comprehension among sender(s) and receiver(s). It is fundamental for building and keeping up with connections in the working environment. Despite the fact that directors invest the majority of their energy conveying (sending or getting data), one can't expect that significant correspondence happens in all trades (Dunn, 2002). When an update, letter, fax, or email has been sent, many are leaned to accept that correspondence has occurred. Be that as it may, correspondence doesn't happen until data and comprehension have passed among source and the planned beneficiary. To get one's point across as expected is a significant piece of correspondence. A beneficiary might hear a shipper yet not get what the source's message implies. Being continually occupied with encoding and interpreting messages doesn't guarantee that a chairman is a specialist in correspondence. Understanding is an individual matter among individuals, and various individuals might decipher messages in an unexpected way. In the event that the thought got isn't the one planned, correspondence has not occurred; the shipper has just spoken or composed.

\section{STATEMENT OF THE PROBLEM}

Perceiving that natural and individual hindrances exist is the initial step to viable correspondence. By becoming cognisant of their reality, one can intentionally limit their effect. Nonetheless, positive activities are expected to conquer these boundaries. Longest et al (2000) give us a few rules for defeating correspondence obstructions:

- Natural hindrances are decreased assuming beneficiaries and shippers guarantee that consideration is given to their messages and that satisfactory time is committed to paying attention to what exactly is being imparted.

- An administration theory that energizes the free progression of correspondence is productive.

- Decreasing the quantity of connections (levels in the hierarchical order or steps between the shipper and the beneficiary lessens potential open doors for bending.

- The power/status obstruction can be taken out by intentionally fitting words and images so that messages are reasonable; supporting words with activities altogether further develops correspondence among various power/status levels. 
- Utilizing numerous channels to build up complex messages diminishes the probability of misconception.

\section{OVERCOMING COMMUNICATION BARRIERS:}

Perceiving that natural and individual boundaries exist is the initial step to viable correspondence. By becoming aware of their reality, one can deliberately limit their effect. Notwithstanding, positive activities are expected to beat these obstructions. Longest et al (2000) give us a few rules for beating correspondence boundaries

- Ecological hindrances are decreased assuming recipients and shippers guarantee that consideration is given to their messages and that sufficient time is given to paying attention to what in particular is being imparted.

- An administration theory that energizes the free progression of correspondence is productive.

- Diminishing the quantity of connections (levels in the hierarchical order or steps between the shipper and the beneficiary decreases open doors for mutilation.

- The power/status hindrance can be taken out by intentionally fitting words and images so that messages are justifiable; building up words with activities fundamentally further develops correspondence among various power/status levels.

- Utilizing various channels to build up complex messages diminishes the probability of misconception.

Individual boundaries to compelling correspondence are decreased by cognizant endeavors of shippers and beneficiaries to see each other's qualities and convictions. One should perceive that individuals participate in particular insight and are inclined to enviously and dread. Imparting compassion to those to whom messages are guided is the most ideal way to increment successful correspondence.

- Use procedures that reach out past conventional authoritative lines to work with correspondence. For example, the utilization of inclining correspondence that moves through teams or boards of trustees improves correspondence all through the association.

- Use the executives processes that are cross-hierarchical rather than restricted to utilitarian or division methods. Executing the executives processes in the space of arranging, controlling, and overseeing data frameworks work with correspondence.

(c) 2022, IJSREM | www.ijsrem.com

DOI: $10.55041 /$ IJSREM11690

Page 3 
- Utilize HR arrangements and strategies (work preparing and work pivot) to improve participation among individuals in associations.

- Use the executives cycles to determine clashes in an impartial way to deliver viable correspondence.

\section{IMPROVING COMMUNICATION EFFECTIVENESS}

When natural and individual boundaries are managed, a way is cleared for further developing correspondence in the association. Powerful correspondence being a two-way process requires exertion and expertise by both source and collector. Heads will on occasion expect every one of these jobs in the correspondence interaction. Considering this, rules for further developing correspondence adequacy, including shippers' and collectors' liabilities are examined beneath

\section{CONCLUSION}

Correspondence in the working environment is basic to laying out and keeping up with quality working connections in associations. As a course of sending data and normal comprehension starting with one individual then onto the next, viable correspondence in the working environment is significant on the grounds that each managerial capacity and movement includes some type of immediate or aberrant correspondence. Thusly, to work on the adequacy of correspondences, directors should foster an attention to the significance of shipper's and beneficiary's liabilities and stick to undivided attention abilities. Powerful relational abilities in the work environment will work on a head's capacity to be a solid chief. Chairmen ought to in this way establish a climate wherein issues, plans, issues, feelings, contemplations and thoughts relating to work, are talked about and taken care of in an expert, capable way through good and successful correspondence.

\section{VII.REFERENCES}

[1] C.K.Gomathy.(2010),"Cloud Computing: Business Management for Effective Service Oriented Architecture" International Journal of Power Control Signal and Computation (IJPCSC), Volume 1, Issue IV, Oct - Dec 2010, P.No:22-27, ISSN: 0976-268X . 
[2] Dr.C K Gomathy, Article: A Study on the recent Advancements in Online Surveying , International Journal of Emerging technologies and Innovative Research ( JETIR ) Volume 5 | Issue 11 | ISSN : 2349-5162, P.No:327-331, Nov-2018

[3] Dr.C.K.Gomathy,C K Hemalatha, Article: A Study On Employee Safety And Health Management International Research Journal Of Engineering And Technology (Irjet)- Volume: 08 Issue: 04 | Apr 2021

[4] Dr.C K Gomathy, Article: A Study on the Effect of Digital Literacy and information Management, IAETSD Journal For Advanced Research In Applied Sciences, Volume 7 Issue 3, P.No-51-57, ISSN NO: 2279-543X,Mar/2018

[5] Dr.C K Gomathy, Article: An Effective Innovation Technology In Enhancing Teaching And Learning Of Knowledge Using Ict Methods, International Journal Of Contemporary Research In Computer Science And Technology (Ijcrcst) E-Issn: 2395-5325 Volume3, Issue 4,P.No-10-13, April ’2017

[6] Dr.C K Gomathy, Article: Supply chain-Impact of importance and Technology in Software Release Management, International Journal of Scientific Research in Computer Science Engineering and Information Technology ( IJSRCSEIT ) Volume 3 | Issue 6 | ISSN : 2456-3307, P.No:1-4, July-2018.

\section{AUTHOR'S PROFILE}

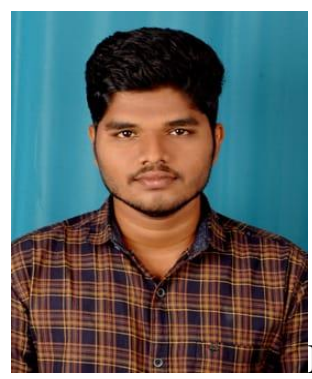

Mr. B.SANDEEP SAI is a B.E. Computer Science and Engineering student at Sri Chandrasekharendra SaraswathiViswa Mahavidyalaya regarded to be a university in Enathur, Kanchipuram, with a specialisation in Big Data Analytics. 
2.

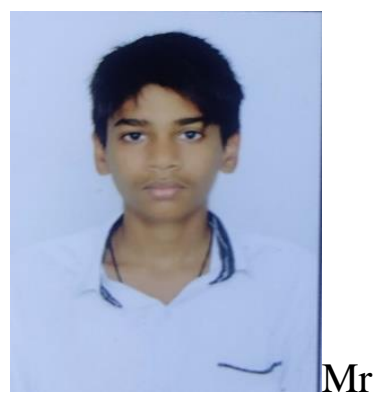

A.PRADEEP REDDY, B.E. Computer Science and Engineering, Sri Chandrasekharendra SarswathiViswa Mahavidyalaya deemed to be university, Enathur, Kanchipuram, India His expertise is in big data analytics.

3.

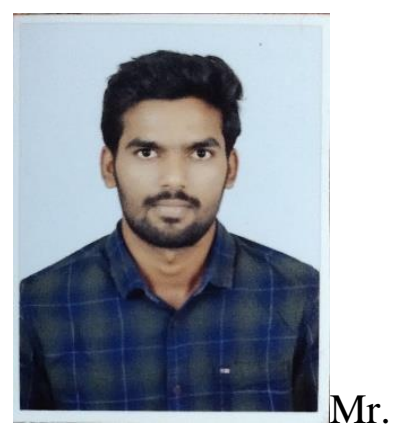

CH.NITISH KUMAR,

B.E. Computer Science and Engineering, sri Chandrasekharendra SarswathiViswa Mahavidyalata deemed to be university Enathur, Kanchipuram, India His expertise is in big data analytics.

4.

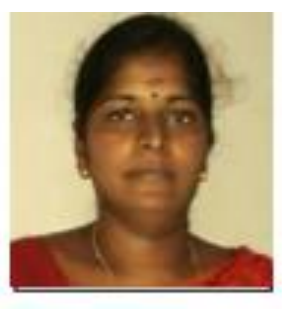

Dr. C. K. Gomathy is an Assistant Professor of Computer Science and Engineering at Sri Chandrasekharendra SarswathiViswa Mahavidyalaya deemed to be university in Enathur, Kanchipuram. Her research interests include Software Engineering, Web Services, Knowledge Management, Internet of Things, Human resource development 